\title{
OBITUARY
}

\section{HARRY LAMBERT LACK, M.D., F.R.C.S.}

HARRY LAMBert LACK, who died on February I4th, began his medical studies at King's College Hospital at the age of 17 . After a brilliant career as a student, in which he carried off most of the possible prizes, he became house surgeon and pathological-assistant to Watson Cheyne. Lister had retired and Cheyne was chiefly responsible for carrying on the methods which revolutionized surgery. Cheyne and Lack worked in close association, and a lasting friendship was established.

Early in life Lack undertook many original investigations, mostly of a pathological nature. He retained interest in pathology all his life, and made frequent use of the microscope as an aid to his clinical work.

After leaving King's he became Resident Medical Officer at Paddington Green Children's Hospital and then at the Throat Hospital, Golden Square. Later on he joined the Staff of both institutions. He was subsequently elected Surgeon to the Throat, Nose, and Ear Department at the London Hospital, and at this Hospital he worked for many years with untiring energy and devotion.

In I899 Lack was awarded the Jacksonian Prize for an essay on "The Pathology, Diagnosis and Treatment of Inflammatory Affection of the Nasal Sinuses and Air-cells". This essay was revised, additional sections added, and in Igo6 his book Diseases of the Nose was published. Every chapter shows signal ability on the part of the author in carrying out investigations, anatomical, pathological and clinical, and as a critic of the work of others. The book remains to-day, after the lapse of twenty-seven years, the most scholarly treatise on the subject in the English language.

Lack was a very good surgeon, and showed himself equally at home in such a delicate manipulation as the removal, under indirect vision, of a nodule from a vocal cord and in such a major procedure as extirpation of the larynx. I think I am right in saying that previous attempts at the London Hospital to perform this operation had been unsuccessful.

He saw the merits of the direct methods of examining the larynx, lower air passages and cesophagus; he soon became expert with the new technique, and he was very 'skilful in removing foreign bodies from the lungs. Another new idea, demonstrated by Naegelschmidt in I9IO, was the treatment of malignant growths by diathermy. Lack was the first person to emfploy this method at the London Hospital, where subsequently many patients were treated by him and his associates with a large measure of success.

He made many important contributions to his speciality. These included investigation into deformity of the upper jaw and teeth resulting from nasal 


\section{Obituary}

obstruction, the nature of fibrinous rhinitis and its relation to diphtheria, and the causation of congenital laryngeal stridor.

He was an accurate observer, and his deductions were always logical, but it was his originality that made his work so valuable.

He had a very kind heart, and delighted in giving pleasure to others; his friendship was something to prize. I worked with him for many years, and have nothing but pleasant memories of the many hours we spent in close association.

Lack, although trained at another institution, was truly loyal to the London Hospital, which held first place in his esteem. In addition to his professional interests he had many others, such as literature, old furniture, gardening, wild birds and golf,

N.P. 